\title{
Bringing Clinics and Hospitals Up-to-speed Amidst COVID-19 Pandemic: Complementing Targeted Point of Care with Pooled Testing Strategy
}

\author{
Rashid A Chotani ${ }^{1-4}$, Syed S. Ashraf ${ }^{3}$, Terry Clark $^{5}$, Charlie Mize ${ }^{6}$, Shakeel M Thakurdas ${ }^{7}$, Khur- \\ ram Nasir ${ }^{8}$ and Faisal $H_{\text {Cheema }}{ }^{7,9,10 *}$ \\ ${ }^{1}$ University of Nebraska Medical Center, USA \\ ${ }^{2}$ IEM, Morrisville, USA
}

${ }^{3}$ CareLife Medical, Fairfax, USA

${ }^{4}$ Washington Vascular Specialists, Takoma Park, USA

${ }^{5}$ Boston Biopharma, Roswell, USA

${ }^{6}$ Matanuska Susitna Regional Hospital, Palmer, USA

${ }^{7}$ InvinciMeD, Houston, USA

${ }^{8}$ Houston Methodist DeBakey Heart and Vascular Center, Houston, USA

${ }^{9}$ HCA Research Institute, Nashville, USA

${ }^{10}$ University of Houston College of Medicine, Houston, USA

*Corresponding author: Faisal H Cheema, Department of Clinical Sciences, University of Houston College of Medicine, HCA Research Institute, 1313 Hermann Dr, Houston, TX 77004, USA

To Cite This Article: Rashid A C, Syed S. A, Terry C, Charlie M, Faisal H Cheema, et al., Bringing Clinics and Hospitals Up-to-speed Amidst COVID-19 Pandemic: Complementing Targeted Point of Care with Pooled Testing Strategy. 2020 - 9(5). AJBSR.MS.ID.001437. DOI: 10.34297/ AJBSR.2020.09.001437.

Received: 㠿 July 02, 2020; Published: 翡 July 30, 2020

\begin{abstract}
The battle against COVID-19 has required extraordinary measures that have adversely affected the US economy and many aspects of American life. Healthcare systems across the world have taken a heavy toll and have had to cancel clinics and elective procedures; open more beds, convert operating rooms into intensive care beds to accommodate COVID-19 patients. Such diversion of resources and delay in medical attention for other health problems has resulted in an increase in non-COVID-19 related mortality throughout the world. In this article we lay out our proposals for a quick reopening of our hospitals and clinics for elective surgeries and other procedures that cannot be handled via telemedicine. The crux of our proposals is a smart COVID-19 screening mechanism that employs several different testing strategies such as point-of-care (POC) rapid antibody test kits, pooled testing and RT-PCR, in a complementary way so as to increase efficiency and feasibility. There is no doubt that for our healthcare system to work and survive, it must not only meet the unprecedented demands generated by COVID-19, but also be able to treat other illnesses and injuries at or close to its pre-pandemic level.
\end{abstract}

Keywords: COVID-19, elective procedures, POC AB testing, pooled testing

\section{Perspective}

To meet the Coronavirus Disease 2019 (COVID-19) pandemic head-on, over the last few months communities and businesses across the United States have had to implement necessary, extraordinary measures. Overburdened healthcare systems across the country have had no choice but to retool hospitals by canceling clinics and elective procedures, assigning more beds for COVID-19 
patients, sometimes converting operating rooms into intensive care beds, and a whole lot more. And many states like Florida and Texas have only now begun to experience a surge in active infections and hospitalizations $[1,2]$.

As we continue to fight the pandemic, we must now adapt to the new normal by displaying strength and resilience to meet not only the needs of those infected by the severe acute respiratory syndrome coronavirus [2] (SARS-CoV-2), but also the demands of those Americans who need medical help due to their baseline illnesses or emergencies similar to pre-pandemic patterns. After several weeks of forsaking, we are now beginning to see that turning our attention away from other illnesses and conditions comes at a serious cost. A recent analysis in The New York Times demonstrated that more Americans died of non-COVID-19 causes in the first 4 months of 2020 than in the first 4 months of 2019 [3]. These findings are consistent also with reports from other countries, which have documented marked increases in all-cause mortality which cannot be fully explained by confirmed COVID-19 deaths. Are those extra deaths the result of COVID-19 and simply not recorded as such? Or, have we been paying so much attention to COVID-19 that we have neglected other threats?

A vital first step forward is to reopen our hospitals and clinics for elective surgeries and other procedures, respectively, that cannot be handled via telemedicine. But considering the COVID-19 pandemic, can we take this step safely? We argue that we can, and we must - and a pragmatic testing strategy for SARS-CoV-2 is the way. Importantly, to be successful this testing approach must achieve two goals: we must test incoming patients to keep our hospital staff and inpatients safe, and test hospital staff to ensure infection does not transmit from the hospital back into vulnerable patients and the community.

The first challenge is to reduce the risk that a patient coming for an elective procedure will spread the virus while being asymptomatic. A recent report from Nature suggests that as many as $40 \%$ of infections occur in the days before patients become symptomatic themselves [4]. The currently available tests will not correctly ascertain all such patients, but they can identify a vast majority of them, thus reducing viral transmission. When coupled with the use of personal protective equipment - the scarcity of which is no longer a lingering quandary - this screening could provide considerable difference in our ability to reopen.

While testing those with symptoms should remain the top priority, there is a need to focus on the asymptomatic individual as well. This will entail a different strategy, accounting for different types of tests and blending their strengths and weaknesses to achieve higher accuracy [Table 1]. The Reverse Transcription Polymerase Chain Reaction (RT-PCR) testing for viral RNA is the first test to become positive, becoming so around 4-5 days after infection, but has a high false negative rate. The test becomes less accurate as time moves on [5]. By contrast, antibody testing typically starts to capture positive cases by day 7 after infection and increasingly accurate afterwards [6].

Table 1: Testing strategies available for COVID-19 diagnosis with their advantages and disadvantages.

\begin{tabular}{|c|c|c|c|c|}
\hline & \multicolumn{2}{|c|}{ Molecular Diagnosis } & \multicolumn{2}{|c|}{ Serologic Test (IgG/IgM) } \\
\hline Objective & \multicolumn{2}{|c|}{ Detection of viral presence } & \multicolumn{2}{|c|}{ Detection of immune response } \\
\hline Technique & RT-PCR & SARS-CoV-2 viral Antigen & ELISA test & $\begin{array}{l}\text { Immuno-chromatographic } \\
\text { assay (rapid test) }\end{array}$ \\
\hline $\begin{array}{l}\text { What does it look } \\
\quad \text { for? }\end{array}$ & $\begin{array}{l}\text { Presence of viral genetic material } \\
\text { (RNA) }\end{array}$ & Presence of viral Antigen & Immune response (Ant & odies) against the virus \\
\hline $\begin{array}{l}\text { What does a +ve test } \\
\text { mean? }\end{array}$ & \multicolumn{2}{|c|}{ Viral presence in patient } & \multicolumn{2}{|c|}{$\begin{array}{l}\text { Patient has been exposed to the virus; is recovering or has } \\
\text { already recovered }\end{array}$} \\
\hline \multirow{2}{*}{$\begin{array}{l}\text { What is the test used } \\
\text { for? }\end{array}$} & \multirow{2}{*}{\multicolumn{2}{|c|}{ To determine if the patient is currently infected }} & \multicolumn{2}{|c|}{ To determine if the patient has been exposed } \\
\hline & & & \multicolumn{2}{|c|}{ (can or cannot spread the disease) } \\
\hline \multirow{3}{*}{ Pros } & \multirow{3}{*}{$\begin{array}{l}\text { - Highly sensitive and specific if } \\
\text { proper technique is used }\end{array}$} & - Rapid & $\begin{array}{l}\text { - More precise than rapid } \\
\text { test }\end{array}$ & - Rapid \\
\hline & & - Simple & $\begin{array}{l}\text { - Provides isolation/ } \\
\text { quarantine information }\end{array}$ & $\begin{array}{l}\text { - } \quad \text { POC (once technique is } \\
\text { validated by FDA) }\end{array}$ \\
\hline & & - Point of Care & & $\begin{array}{l}\text { - Less resource intensive } \\
\text { compared to ELISA }\end{array}$ \\
\hline \multirow{5}{*}{ Cons } & - Labor intensive & - Complex to develop & \multicolumn{2}{|c|}{ - Possible false negative if performed early in infection } \\
\hline & $\begin{array}{l}\text { Tests have to be processed in } \\
\text { labs (1-2 days to get results) }\end{array}$ & - Complex to validate & \multicolumn{2}{|c|}{$\begin{array}{l}\text { - Possible false positive due to interaction with other } \\
\text { viruses and strains of coronavirus }\end{array}$} \\
\hline & $\begin{array}{l}\text { - Risk of false negative (bad } \\
\text { sampling; bad technique) }\end{array}$ & & & \\
\hline & - Not all labs can process & & & \\
\hline & - Shortage of swabs & & & \\
\hline
\end{tabular}




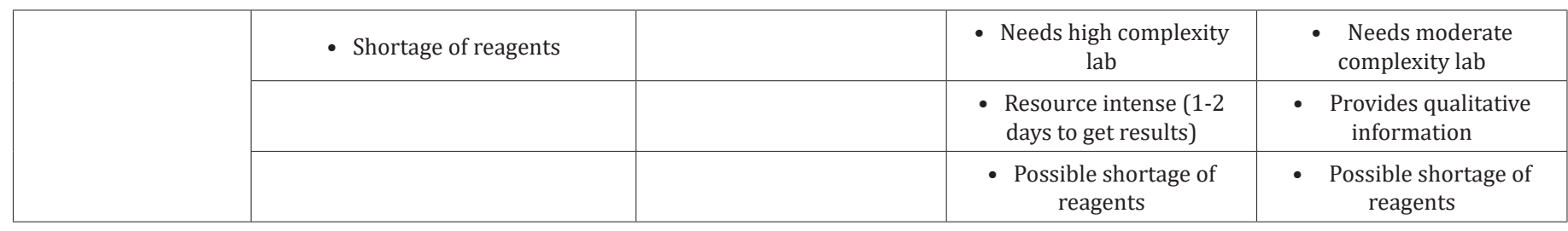

Interpretation of these results can be relatively straightforward and could be presented as an 'if-then' grid of possible results and consequent actions. Some examples: if someone has a positive RNA test - delay the procedure. Likewise, if a patient demonstrates a positive IgM antibody test, suggestive of acute infection - similarly delay the procedure. Even if the IgM represents a false positive, erring on the side of staff protection and retesting in a week is the prudent course. The body creates IgG antibodies as part of a long-term, sustained immune response. When a test demonstrates negative SARS-CoV-2 RNA, negative IgM and positive IgG antibodies, we can assume recovery from past infection and proceed. All three tests negative? Assume SARS-CoV-2 negative and proceed.

Testing medical staff represents the other challenge. If carried out indiscriminately, regular testing of large, asymptomatic groups can entail a logistical and financial burden upon the laboratory of any hospital or clinic - especially when testing capabilities are limited and supplies of reagents paltry. To meet this challenge, two plausible solutions are point-of-care (POC) antibody testing or pooled testing.

The POC antibody testing approach has the ability to test large numbers of suspected cases even when swift access to a central laboratory is not available, and that warrants acting quickly upon test results that arrive within minutes of the test. With low disease prevalence, positive POC antibody test results would require confirmation by PCR or a formal serology testing in a laboratory. But while awaiting those results - and owing the rapid POC testing capability - the team is equipped to take provisional action to protect other members of the staff. Additionally, antibody screening can reveal the prevalence of prior infections and shed light on the prevalence of SARS-CoV-2 in the population being examined.

The alternative solution entails the use of pooled testing that enables the testing of large groups with relatively few tests [7-12]. It is also known as the Dorfman Method, named in honor of the scientist who first employed this system to test US Army recruits for syphilis [13]. When most tests are negative, pooling reduces the total number of tests up to four-fold at a disease prevalence of $2 \%$ prevalence and eight-fold when prevalence is $0.5 \%$. This efficiency is important because the overall incidence of SARS-CoV-2 is low, even in communities hit hard by the virus. Since its first application, pooled testing has been successfully employed to test the donor blood supply, to sample for influenza and to examine the prevalence of West Nile Virus in mosquitoes. The concept is simple: instead of testing each individual separately, the samples from a large number of individuals are divided into a few groups, so that only a few tests are run where each run comprises of a group as a whole. If the test is negative, the entire group is considered free of disease. If the group is positive, subgroups are then tested in series until successful identification of the positive individual or individuals. These will be the cases that triggered the positive result for the group and thus targeted cascade for quarantine and treatment strategies may ensue for those individuals.

Recent experience shows that a single positive result from RNA from SARS-CoV-2 testing will still test positive after the addition of 63 negative samples, demonstrating that pooled testing can be attempted in COVID-19 [14]. In addition, the process lends itself to increasing efficiency. Once enough tests are done to understand which populations are at higher risk (for example, emergency physicians) and which are at lower risk (for example, workers in a Ford plant), a tailored size of each testing group to the risk of illness borne by that group. Thus, minimizing further the number of tests. The efficiency of the Dorfman Method is increases by testing high-risk groups in smaller groups (for example, one group for ten emergency physicians) and lower-risk groups in larger groups (for example, one group for one-hundred technicians in a car plant). Using a pooled testing strategy shall enormously reduce the burden on healthcare amidst this pandemic.

As we continue our fight against this pandemic, we must adapt to the new normal by meeting the needs of not only those with COVID-19, but also of those Americans who necessitate medical help for reasons not related to the pandemic. There is no doubt that for our health systems to work (and survive) they must not only meet the unprecedented demands generated by COVID-19, but concurrently be able to continue to treat other illnesses and injuries corresponding to the pre-pandemic disease patterns. Hospitals and clinics must reopen, but to do so safely, they must employ wise testing strategies that embrace systematic clinical evaluations, as well as antibody and viral RNA testing. A pooled testing strategy could pave the way for a rapid reopening of clinics and hospitals, and it could do it at a fraction of the cost. Only by carefully combining targeted POC and pooled testing can we ensure that our patients receive great care even in the face of COVID-19.

\section{Reference}

1. Fowler H (2020) Hospital bed capacity helps states measure COVID-19 spread. Here's why it matters. 
2. (2020) About 75\% of adult ICU beds occupied in Florida - and twothirds in Jacksonville.

3. Josh Katz, Denise DL, Margot SK (2020) U.S. Coronavirus Death Toll Is Far Higher Than Reported, CDC. Data Suggests.

4. He X, Lau EHY, Wu P, Deng X, Wang J, et al. (2020) Temporal dynamics in viral shedding and transmissibility of COVID-19. Nat Med 26: 672-675.

5. Pan Y, Zhang D, Yang P, Poon LLM, Wang Q (2020) Viral load of SARSCoV-2 in clinical samples. Lancet Infect Dis 20(4): 411-412.

6. Warrington R, Watson W, Kim HL, Antonetti FR (2011) An introduction to immunology and immunopathology. Allergy Asthma Clin Immunol 7(Suppl 1): S1.

7. Mcmahan CS, Tebbs JM, Bilder CR (2012) Informative Dorfman Screening. Biometrics 68(1): 287-296.

8. Roques L, Klein E, Papaix J, Soubeyrand S (2020) Mechanistic-statistical SIR modelling for early estimation of the actual number of cases and mortality rate from COVID-19. medRxiv.
9. Bilder CR, Tebbs JM (2012) Pooled-testing procedures for screening high volume clinical specimens in heterogeneous populations. Stat Med 31(27): 3261-3268.

10. Lohse S, Pfuhl T, Berkó Göttel B, Rissland J, Geißler T, et al. (2020) Pooling of samples for testing for SARS-CoV-2 in asymptomatic people. Lancet Infect Dis S1473-3099(20)30362-30365.

11. Deckert A, Bärnighausen T, Kyei N (2020) Pooled-sample analysis strategies for COVID-19 mass testing: a simulation study Running title: Analysis strategies for COVID-19 mass testing. Bull World Heal Organ.

12. Shani Narkiss H, Gilday OD, Yayon N, Landau ID (2020) Efficient and Practical Sample Pooling High-Throughput PCR Diagnosis of COVID-19. medRxiv.

13. Dorfman R (1943) The Detection of Defective Members of Large Populations. Ann Math Statist 14(4): 436-440.

14. Yelin I, Aharony N, Shaer Tamar E, Argoetti A, Masser E, et al. (2020) Evaluation of COVID-19 RT-qPCR test in multi-sample pools. Clin Infect Dis. 